\title{
Thermal Stability and Kinetics of Thermal Decomposition of Statistical Copolymers of N-Vinylpyrrolidone and Alkyl Methacrylates Synthesized via RAFT Polymerization
}

\author{
Theodoros Gikarakis, Ioannis Pappas, Pothiti Arvanitaki, Ekaterini Pantazi, \\ Eleftheria Mitsoni, Nikoletta Roka $\mathbb{D}$, and Marinos Pitsikalis \\ Industrial Chemistry Laboratory, Department of Chemistry, National and Kapodistrian University of Athens, \\ Panepistimiopolis Zografou, Athens 15771, Greece \\ Correspondence should be addressed to Marinos Pitsikalis; pitsikalis@chem.uoa.gr
}

Received 9 December 2020; Revised 24 February 2021; Accepted 11 March 2021; Published 19 March 2021

Academic Editor: Shin ichi Yusa

Copyright (c) 2021 Theodoros Gikarakis et al. This is an open access article distributed under the Creative Commons Attribution License, which permits unrestricted use, distribution, and reproduction in any medium, provided the original work is properly cited.

\begin{abstract}
The thermal stability and the kinetics of thermal decomposition of statistical copolymers of N-vinylpyrrolidone (NVP) with the alkyl methacrylates, hexyl methacrylate (HMA) and stearyl methacrylate (SMA), were studied by Thermogravimetric Analysis (TGA) and Differential Thermogravimetry (DTG). Statistical copolymers of different compositions were studied, and their thermal decomposition behavior was compared to the corresponding homopolymers. The activation energies of the thermal decomposition were calculated using the Ozawa-Flynn-Wall, the Kissinger, and the Kissinger-Akahira-Sunose methodologies. The effects of the nature of the methacrylate monomer, the copolymer composition, and the rate of heating are discussed.
\end{abstract}

\section{Introduction}

There is a continuous effort towards the synthesis of novel polymeric materials to cover the needs for modern everyday life and for specialty applications as well $[1,2]$. Towards this goal, the employment of new monomers as the source of novel polymers is limited and therefore the research is directed to the combination of different monomers with diverse properties, leading to the synthesis of copolymers with various architectures [3-17]. Both parameters, that is, the macromolecular architecture and the coexistence in the same structure of two or more monomer units, may dramatically influence the solid state and solution properties $[18,19]$. Among the various architectures, the most commonly employed in the literature and the most promising even for industrial applications are the statistical copolymers. Statistical copolymerization is the most convenient way to produce tailor-made polymers. The copolymer composition, the distribution, and the mean sequence length of the monomer units along the copolymeric chain are key parameters to elucidate the properties of the final product. An enormous amount of work, both experimental and theoretical, confirms the significance of statistical copolymerization in polymer science [20-33].

Various polymerization techniques have been employed over the years for the synthesis of statistical copolymers. Among them, the controlled radical polymerization methods combine two very important characteristics: control over the molecular characteristics and experimental simplicity that can be further extended even to industrial applications [34]. Over the last decade, special interest has been dedicated to the Reversible Addition-Fragmentation chain Transfer (RAFT) process. The RAFT protocol can be applied to a wide variety of monomers, even those bearing functional groups, and can be conducted in various solvents, including water and other protic media. Furthermore, polymers of controlled molecular weights and low polydispersity and with complex architecture can be obtained [35-39]. 
In this work, statistical copolymers of $\mathrm{N}$-vinylpyrrolidone (NVP) with the alkyl methacrylates, hexyl methacrylate (HMA) and stearyl methacrylate (SMA), were used. In a previous study, the copolymerization behavior of NVP with either HMA or SMA was studied with regard to terminal and the penultimate copolymerization models [40]. The reactivity ratios were calculated using several methodologies along with structural characteristics of the copolymer chain. The thermal properties of the copolymers were studied by Differential Scanning Calorimetry (DSC), Thermogravimetric Analysis (TGA), and Differential Thermogravimetry (DTG) and were compared to those obtained from the corresponding homopolymers.

Poly(N-vinylpyrrolidone) (PNVP) is a very important polymer for both academia and industry. This is due to its solubility both in aqueous media and in organic solvents, leading to the synthesis of amphiphilic and double-hydrophilic polymers. In addition, it is characterized by low toxicity, biocompatibility, and high complexing ability. Therefore, it can find applications in several industrial sectors, such as cosmetics and pharmaceuticals. It is a nonionic, amorphous polymer, with the characteristic feature that it does not show a lower critical solution temperature behavior in aqueous solutions. This last unique feature is the major benefit of PNVP compared to poly(ethylene oxide), a nonionic, hydrophilic crystalline polymer preferably used in industry, as a water-soluble polymer [41-47].

Most of the polymers are practically used as solid materials. Therefore, it is imperative to study their thermal properties to find the suitable range of temperatures for possible applications $[48,49]$. Towards this direction, thermal analysis methods are extremely valuable tools to provide information regarding the thermal transitions, the thermal stability, and the thermal decomposition of novel polymeric materials. The isoconversional methods in isothermal and nonisothermal kinetics can be applied to avoid ambiguities having to do with the specific decomposition reaction model, which is followed [50-52]. This approach is strongly recommended by the kinetics committee of the International Confederation for Thermal Analysis and Calorimetry (ICTAC), since it provides more reliable kinetic parameters [53-55]. The present study is focused on the thermal stability and the kinetics of the thermal decomposition of statistical copolymers of NVP with HMA and SMA. The nature of the methacrylate comonomer, the copolymer composition, and the arrangement of the various monomer units along the polymer chain play an important role in determining the decomposition process of these novel copolymers. The coexistence of sequences of different monomer units with different thermal stabilities and decomposition profiles renders the mechanism of the thermal decomposition process very complex. The estimation of the activation energy of the thermal decomposition process is carried out, mainly using nonisothermal isoconversional methods, since they are not affected by the exact reaction model in solid-state decomposition kinetics.

\section{Materials and Methods}

The synthesis of the statistical copolymers has been reported previously [40]. The copolymerizations were conducted either in bulk or in dry tetrahydrofuran (THF) solutions using 2,2'-azobisisobutyronitrile (AIBN) as initiator and [1(O-ethylxanthyl)ethyl]benzene as the chain transfer agent (CTA).

A set of five copolymers of NVP and each alkyl methacrylate (RMA) was prepared. Different feed ratios were involved in each copolymerization (monomer molar ratios NVP/RMA: 80-20, 60-40, 50-50, 40-60, and 20-80). Various copolymers are denoted by the respective feed molar ratios of the monomers; for example, sample PNVPco-PHMA 20-80 corresponds to the copolymer synthesized by using $20 \% \mathrm{NVP}$ and $80 \%$ HMA as molar feed composition. The copolymerization procedure was monitored by size exclusion chromatography (SEC) and ${ }^{1} \mathrm{H}-\mathrm{NMR}$ spectroscopy.

The thermal stability of the copolymers was studied by Thermogravimetric Analysis (TGA) employing a Q50 TGA model from TA Instruments. The samples were placed in a platinum pan and heated from ambient temperatures to $600^{\circ} \mathrm{C}$ in a $60 \mathrm{~mL} / \mathrm{min}$ flow of nitrogen at heating rates of 3,5 , $7,10,15$, and $20^{\circ} \mathrm{C} / \mathrm{min}$.

\section{Results and Discussion}

3.1. Statistical Copolymers of NVP and HMA or SMA via RAFT. The RAFT copolymerization of NVP and HMA was conducted in bulk, for $35 \mathrm{~min}$, at $60^{\circ} \mathrm{C}$ and with SMA in THF, for 3 hours, using AIBN as initiator and [1-(O-ethylxanthyl)ethyl]benzene as the CTA (Scheme 1).

Several copolymers with different feed compositions were prepared. Their molecular characteristics are given in Table 1. The molecular weights and polydispersity were measured by SEC in $\mathrm{CHCl}_{3}$ as the carrier solvent, while the copolymer composition was measured by ${ }^{1} \mathrm{H}-\mathrm{NMR}$.

All the samples have high molecular weights and relatively narrow molar mass distribution, in the range expected for RAFT polymerization [56]. Apparently, the CTA provided a good control over the molar mass distribution.

\subsection{Thermal Stability of the Homopolymers and the Statistical} Copolymers. The thermal stability and kinetics of the thermal decomposition of the statistical copolymers and the respective homopolymers were studied by Thermogravimetric Analysis (TGA) and Differential Thermogravimetry (DTG). Characteristic thermograms from the TGA and DTG measurements are given in Figures 1 and 2 for the PNVP-co-PSMA and PNVP-co-PHMA copolymers, whereas more data are provided in the Supplementary Materials section (SMS, Figures S1-S11). Tables containing detailed data regarding the range of thermal decomposition (temperatures of initiation and completion of the thermal decomposition, along with the temperature at the highest rate of thermal decomposition) are displayed in the SMS, as 


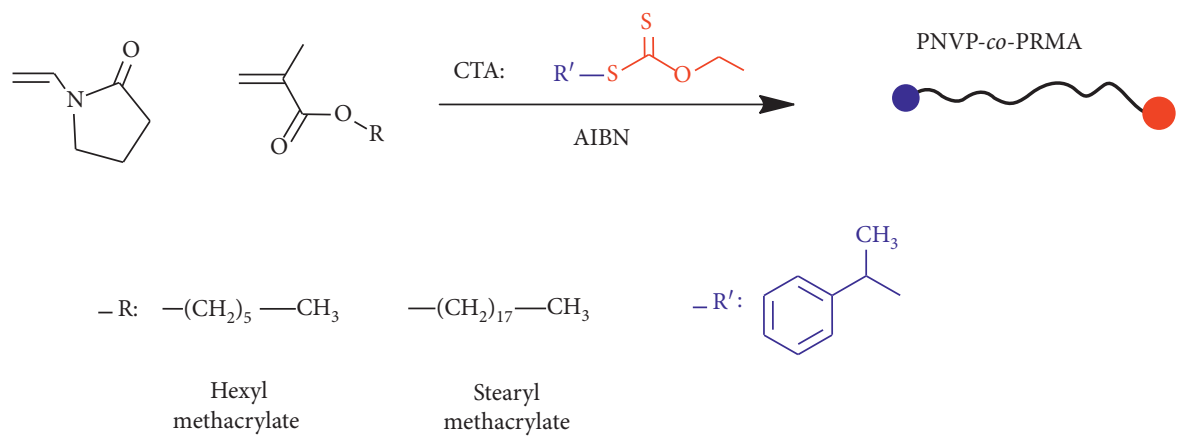

Scheme 1: Synthetic route for the synthesis of the statistical copolymers PNVP-co-PRMA via RAFT.

TABLE 1: Molecular characteristics of the PNVP-co-PRMA copolymers synthesized via RAFT.

\begin{tabular}{|c|c|c|c|c|c|}
\hline Sample & $\mathrm{M}_{\mathrm{w}} \mathrm{x} 10^{-3}{\text { (Daltons })^{\mathrm{c}}}$ & $\bigoplus^{c}$ & Monomer conversion (\%) & (\%) Mol NVP ${ }^{\mathrm{d}}$ & $(\%)$ Mol RMA ${ }^{\mathrm{d}}$ \\
\hline 80-20 PNVP-co-PHMA ${ }^{\mathrm{a}}$ & 133 & 1.4 & 6 & 35 & 65 \\
\hline $60-40$ & 265 & 1.4 & 10 & 30 & 70 \\
\hline $50-50$ & 265 & 1.4 & 17 & 27 & 73 \\
\hline $40-60$ & 228 & 1.4 & 7 & 25 & 75 \\
\hline $20-80$ & 282 & 1.3 & 14 & 23 & 77 \\
\hline 80-20PNVP-co-PSMA ${ }^{\mathrm{b}}$ & 95 & 1.6 & 30 & 51 & 49 \\
\hline $60-40$ & 143 & 1.5 & 22 & 36 & 64 \\
\hline $50-50$ & 171 & 1.5 & 25 & 34 & 66 \\
\hline $40-60$ & 243 & 1.6 & 33 & 32 & 68 \\
\hline $20-80$ & 216 & 1.4 & 27 & 19 & 81 \\
\hline
\end{tabular}

${ }^{\mathrm{a}}$ Conditions: bulk $/ 60{ }^{\circ} \mathrm{C} / 35 \mathrm{~min} .{ }^{\mathrm{b}} \mathrm{Conditions:} \mathrm{THF} / 60{ }^{\circ} \mathrm{C} / 3$ hours. ${ }^{\mathrm{c}} \mathrm{By} \mathrm{SEC}$ in $\mathrm{CHCl}_{3} .{ }^{\mathrm{d}} \mathrm{By}{ }^{1} \mathrm{H}-\mathrm{NMR}$.

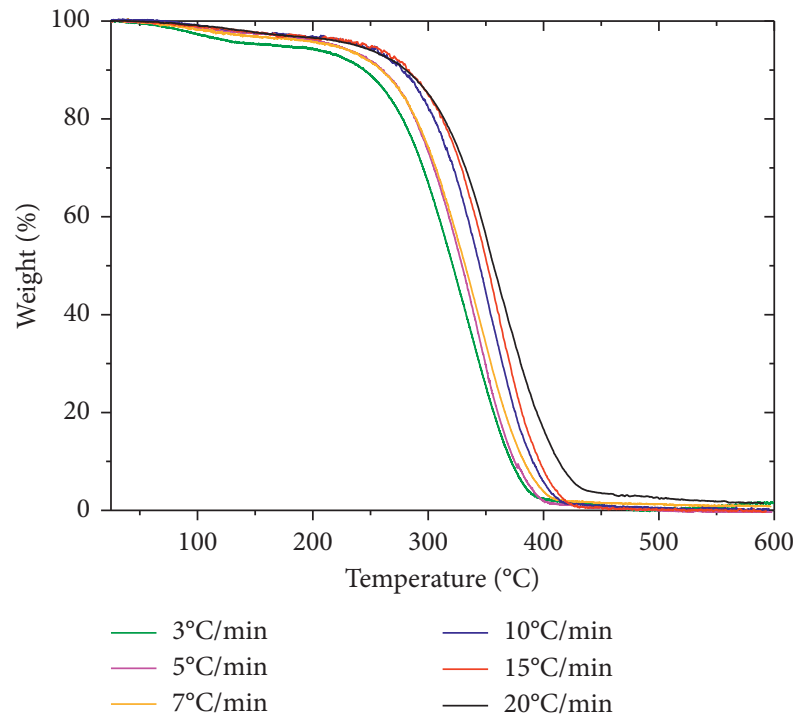

(a)

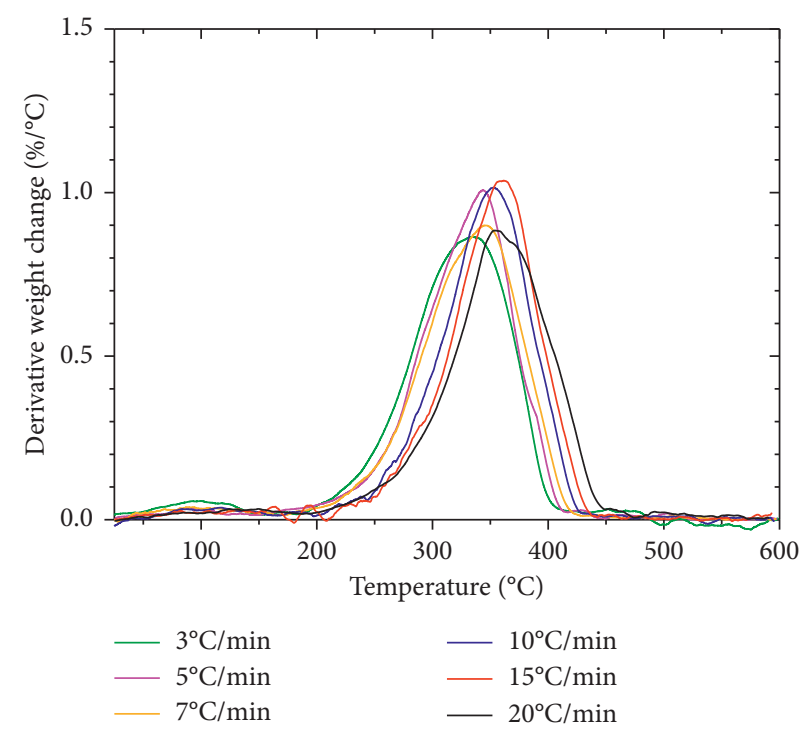

(b)

Figure 1: (a) TGA curves for sample PNVP-co-PSMA 20-80 under different heating rates. (b) Derivative weight loss with temperature for sample PNVP-co-PSMA 20-80 under different heating rates.

well, for different rates of heating and for all homopolymers and copolymers (Tables S1-S12).

In both cases of homopolymers and copolymers, a shift of the onset of decomposition to higher temperatures was observed upon increasing the heating rate. This effect is rather common and can be attributed to the shorter time of heating required for a sample to reach a given temperature at the faster heating rate. In the case of the PNVP homopolymer, a single decomposition maximum is obtained between 415 and $451^{\circ} \mathrm{C}$, indicating that a rather simple mechanism of 


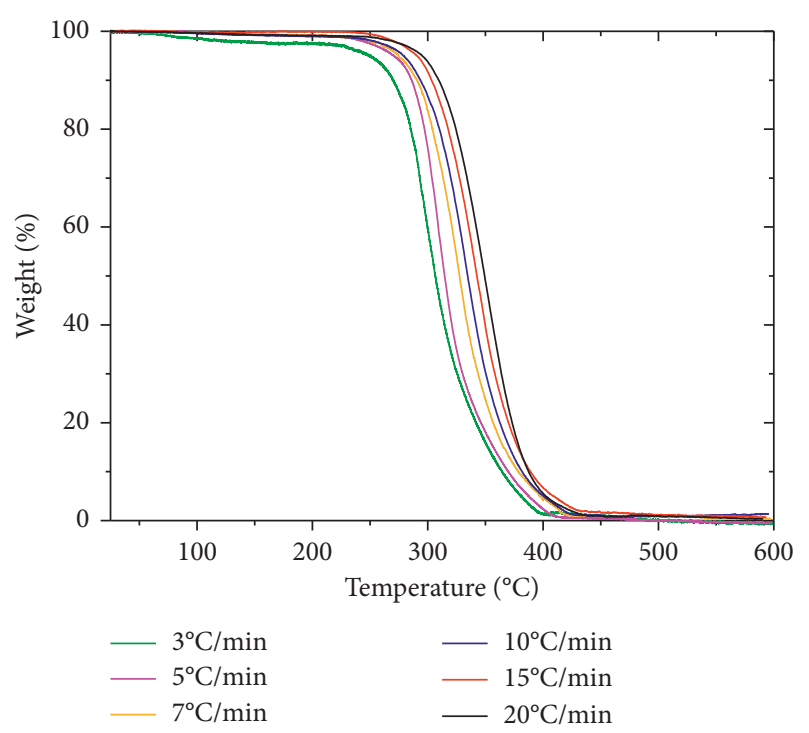

(a)

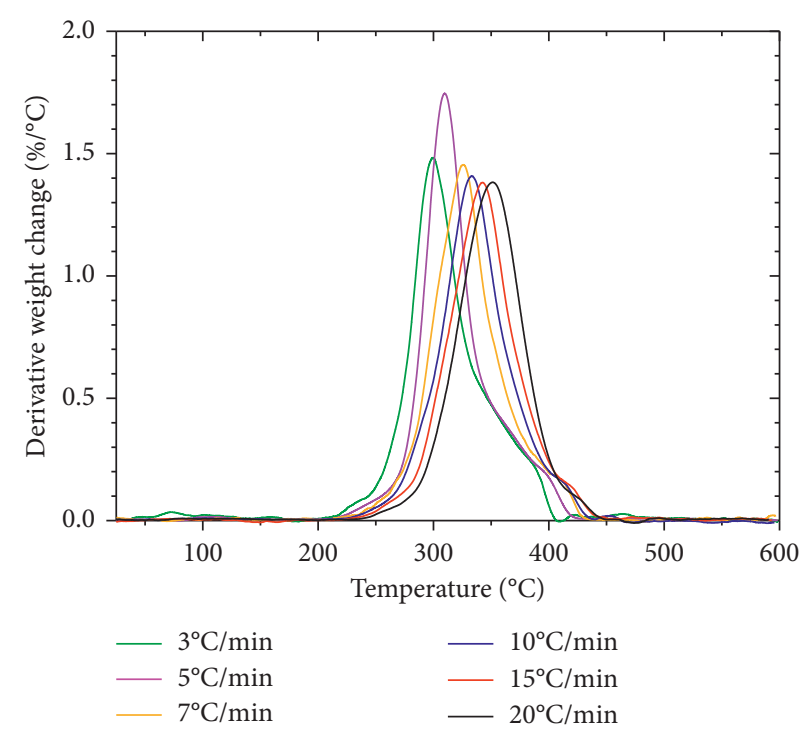

(b)

Figure 2: (a) TGA curves for sample PNVP-co-PHMA 20-80 under different heating rates. (b) Derivative weight loss with temperature for sample PNVP-co-PHMA 20-80 under different heating rates.

decomposition is effective. This result can be attributed to the predominant depolymerization mechanism leading to the formation of monomers of the polymeric main chain, along with simultaneous reactions yielding oligomers $[57,58]$.

On the other hand, for both homopolymers, PSMA and PHMA, DTG analysis revealed the presence of single decomposition peaks. The decomposition maxima were obtained in the temperature range of $270-330^{\circ} \mathrm{C}$ for PSMA and $282-320^{\circ} \mathrm{C}$ for PHMA. However, in both cases and especially at lower rates of heating, a small shoulder or even a second decomposition peak was observed at lower temperatures, in the $180-270^{\circ} \mathrm{C}$ range. Similar results have been revealed for other polymethacrylate homopolymers, prepared by RAFT. In particular, poly(benzyl methacrylate), PBzMA, showed two steps of thermal decomposition [59]. The first was located at $275-300^{\circ} \mathrm{C}$, corresponding to about $20 \%$ loss of weight, whereas the second step was located at $340-460^{\circ} \mathrm{C}$. Poly(2-(dimethylamino)ethyl methacrylate), PDMAEMA, showed a similar behavior [60]. At the range of $303-352^{\circ} \mathrm{C}$, a weight loss of $60 \%$ was observed, whereas the second decomposition step was found at the range of $403-437^{\circ} \mathrm{C}$.

These data confirm that the mechanism of thermal decomposition of the polymethacrylates is rather complex, initially involving the decomposition of the ester group, followed by the thermal decomposition of the main chain. The thermal stability of the various homopolymers seems to be increased in the order $\mathrm{PHMA} \approx \mathrm{PSMA}<\mathrm{PDMAEMA}<\mathrm{PBzMA}$. The aromatic ester groups of PBzMA provide high thermal stability to the polymer chain. On the other hand, the polar dimethylamino side groups of PDMAEMA introduce strong intra- and intermolecular interactions leading to high thermal stability as well. The alkyl ester moieties are definitely the most thermal labile groups. It is expected that, upon increasing the size of the alkyl ester group, the thermal stability decreases. However, this effect is overbalanced by the ability of the long alkyl side chains to form crystalline domains (side chain crystallization). Therefore, more energy is needed to overcome the attractive forces of the crystalline lattice and achieve thermal decomposition of the polymer. Therefore, PSMA and PHMA have similar thermal stability.

DTG measurements revealed the presence of single decomposition curves for the PNVP-co-PSMA copolymers. This peak is not always symmetric, since it is a result of the thermal decomposition of sequences involving a mixture of two different monomer units with distinct and respective thermal behavior. In the case of the PNVP-co-PHMA copolymers, a somewhat different behavior was obtained. A shoulder or even a separate decomposition peak was observed. This effect was more pronounced at lower rates of heating and can be attributed to (a) the different thermal stability of the two homopolymers, with the PNVP being much more thermally stable than PHMA, and (b) the fact that the statistical copolymers, as revealed by the monomer reactivity ratios, do not have a random distribution of the two monomer units but rather a gradient structure with large PHMA and PNVP sequences. The more complex copolymerization route of HMA with NVP (exclusively following the penultimate copolymerization model) compared to SMA and NVP (where the more classic terminal copolymerization model can be adopted) [40] may be responsible for the specific DTG decomposition profiles.

For both types of statistical copolymers, it was observed that the temperature at the maximum rate of thermal decomposition falls within the values of the two respective homopolymers. This is a result of the statistical distribution of the various monomer units along the copolymer chain. Only in pure block copolymers are separate thermal decomposition curves expected, corresponding to each distinct block, provided that these blocks have a different thermal 
stability. In addition, for the same sample, the decomposition temperature at the maximum rate increased upon increasing the rate of heating, as previously mentioned for the homopolymers. Finally, for the same rate of heating, the decomposition temperature at the maximum rate increased upon increasing the PNVP content. This is reasonable, since PNVP is thermally much more stable than PSMA and PHMA homopolymers. Therefore, both the nature and the composition of the copolymers may affect the thermal stability of the copolymeric structures.

3.3. Kinetics of the Thermal Decomposition of the Homopolymers and the Statistical Copolymers. The reaction rate of the thermal decomposition reaction is expressed as a function of conversion $\alpha$ and temperature $T$ as

$$
\frac{\mathrm{d} \alpha}{\mathrm{d} t}=f(\alpha) k(T),
$$

where $t$ is time, $\alpha$ is the conversion of the decomposition reaction, and $f(\alpha)$ is the differential conversion function. The dependance on the temperature can be an Arrhenius equation, that is,

$$
k(T)=A e^{-E a / R T},
$$

where $\mathrm{A}$ is the preexponential factor $\left(\mathrm{min}^{-1}\right), E \alpha$ is the activation energy, and $R$ is the gas constant $\left(8.314 \mathrm{~J} \mathrm{~mol}^{-1}\right.$. $\mathrm{K}^{-1}$ ). Substituting (2) into (1) affords

$$
\frac{\mathrm{d} \alpha}{\mathrm{d} t}=A e^{-E a / R T} f(\alpha),
$$

In case the heating rate $\beta$ is constant, that is,

$$
\beta=\frac{\mathrm{d} T}{\mathrm{~d} t},
$$

equation (3) is transformed to

$$
\frac{\mathrm{d} \alpha}{\mathrm{d} T}=\left(\frac{A}{\beta}\right) e^{-E a / R T} f(\alpha),
$$

or else

$$
\frac{\mathrm{d} \alpha}{f(\alpha)}=\left(\frac{A}{\beta}\right) e^{-E a / R T} \mathrm{~d} T \text {. }
$$

Upon integrating equation (6), the result is the following:

$$
\begin{aligned}
g(a) & =\int_{0}^{a} \frac{\mathrm{d} a}{f(a)}, \\
& =\frac{A}{\beta} \int_{T o}^{T} e^{-E a / R T} \mathrm{~d} T, \\
& =\frac{A E a}{\beta R} P(x),
\end{aligned}
$$

where $T o$ and $T$ are the initial and final temperatures of the reaction, respectively. $g(\alpha)$ is the integral conversion function and $x=E \alpha /$ RT [61-66]. As it is obvious, $g(\alpha)$ depends on the conversion mechanism and its mathematical model. Several algebraic expressions of functions of the most common reaction mechanisms operating in solid state reactions are given in the literature [67]. The $P(x)$ function has no analytical solution. Therefore, several approximate expressions have been suggested. Among them are the following:

$$
P(x)=0.0048 e^{(-1.0516 x)},
$$

and

$$
P(x)=\frac{e^{(-x)}}{x^{2}} .
$$

Substitution of equations (8) and (9) into equation (7) results in the very-well-known Ozawa-Flynn-Wall (OFW) [68-70] and Kissinger-Akahira-Sunose (KAS) [71] equations:

OFW:

$$
\ln \beta=\ln \left[\frac{0.0048 A E a}{g(a) R}\right]-1.0516 \frac{E a}{R T},
$$

KAS:

$$
\ln \frac{\beta}{T^{2}}=\ln \left[\frac{A E a}{g(a) R}\right]-\frac{E a}{R T} .
$$

These methodologies belong to the isoconversional approaches and are "model free" methods, taking into account the fact that the conversion function $f(\alpha)$ is not affected by the change of the heating rate, $\beta$, for all values of $\alpha$. Therefore, plotting $\ln \beta$ versus $1 / T$ or $\ln \left(\beta / T^{2}\right)$ versus $1 / T$, respectively, should provide straight lines with slope directly proportional to the activation energy. Furthermore, if the determined activation energy values do not appreciably vary with various values of $\alpha$, then a single-step degradation reaction can be concluded.

The OFW and KAS methods involve the measuring of the temperatures corresponding to fixed values of $\alpha$ from experiments at different heating rates $\beta$. Both approaches are very useful for the kinetic interpretation of thermogravimetric data, obtained from complex processes like the thermal degradation of polymers and can be applied without knowing the reaction order of the decomposition process. The OFW method is based on the Doyle approximation (leading to equation 8) [72], whereas the KAS method is based on the more precise Coats and Redfern approximation (leading to equation 9) [73]. Therefore, the latter approach is considered to provide higher accuracy in the determination of the activation energy of the thermal decomposition process.

In addition to these isoconversional methods, the Kissinger method can also be applied to provide the activation energy $E \alpha$ [74]. It is based on the equation

$$
\ln \left(\frac{\beta}{T p^{2}}\right)=\ln \left(\frac{A R}{E \alpha}\right)+\ln \left[n\left(1-\alpha_{p}\right)^{n-1}\right]-\left(\frac{E \alpha}{R T p}\right),
$$

where $T p$ and $\alpha_{\mathrm{p}}$ are the absolute temperature and the conversion at the maximum weight loss and $n$ is the reaction order of the decomposition process. The $E \alpha$ values can be 
calculated from the slope of the plots of $\ln \left(\beta / T p^{2}\right)$ versus $1 /$ Tp.

At first glance, equations (11) and (12) look similar. However, this is not the case. The Kissinger equation involves $T p$, which is the temperature at the maximum weight loss and produces a single value of activation energy for the whole thermal decomposition process. This does not mean that there is no variation of $E \alpha$ throughout the polymer decomposition. However, the $E \alpha$ value at the conversion corresponding to the maximum weight loss is considered as the most representative for each sample. In conclusion, this is the most questionable method and with higher uncertainties in evaluating the activation energy compared to the classical isoconversional methods, OFW and KAS. However, due to its simplicity, it is still in use in the literature.

Characteristic plots employing the Kissinger methodology are displayed in Figures 3 and 4, whereas example plots employing the OFW methodology are given in Figures 5 and 6. Finally, representative plots from the KAS methodology are shown in Figures 7 and 8. The activation energies calculated by the Kissinger methodology for all samples are shown in Table 2, whereas those obtained by the OFW approach are shown in Table 3 for the PNVP-co-PSMA and in Table 4 for the PNVP-co-PHMA copolymers, respectively. The corresponding results from the KAS method are incorporated in Tables 5 and 6 . More plots from both graphical procedures are included in the SMS (Figures S12-S22 for the Kissinger plots, Figures S23-S33 for the OFW plots, and Figures S34-S41 for the KAS plots).

The Kissinger and the OFW plots for the PNVP and the polymethacrylate homopolymers are more or less linear, meaning that both methods provide reliable results regarding the kinetics of their thermal decomposition. This conclusion is further evidenced by the fact that the activation energies calculated by both methodologies are in relatively close agreement. The variation of $E \alpha$ values with the conversion from the OFW plots is very small for PNVP, indicating the presence of a rather simple thermal degradation mechanism. However, a different situation was obtained for the polymethacrylate homopolymers, where the variation was considerably increased. This is a direct evidence of the presence of a more complex thermal degradation mechanism for these polymers, in agreement with our previous observations, regarding the study of thermal degradation of PBzMA [59] and PDMAEMA [60]. The E $\alpha$ values from the Kissinger methodology for PBzMA and PDMAEMA are also incorporated in Table 2 for comparison. It is clear that the thermal stability of the homopolymers is confirmed by these results, verifying that PNVP is the most thermally stable polymer among the other samples.

The activation energies measured by the Kissinger methodology for the statistical copolymers are generally within the values obtained for the respective homopolymers. However, there are samples with $E \alpha$ values higher or lower than the corresponding values of the homopolymers. This experimental finding implies that both the composition and, most importantly, the sequence of the monomer units along the copolymeric chain play an important role in defining the kinetics of the thermal decomposition of the copolymers.

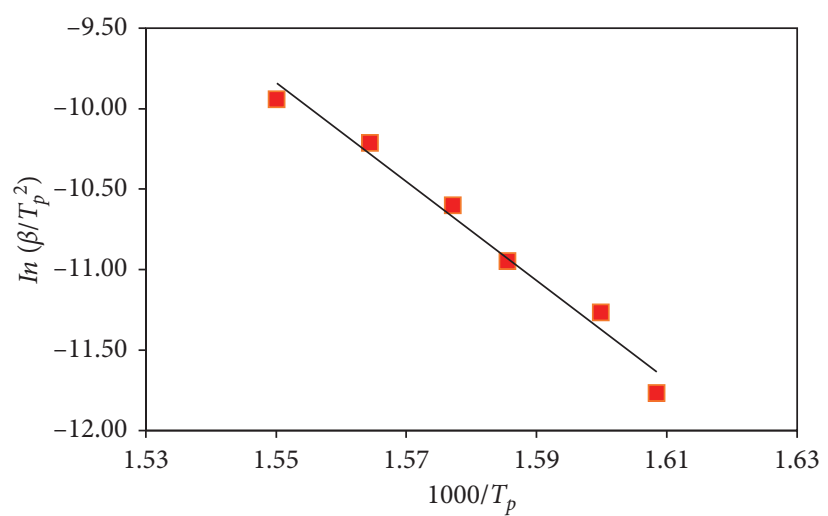

FIgURE 3: Kissinger plot $\ln \left(\beta / T_{p}^{2}\right)$ versus $1000 / T_{\mathrm{p}}$ for sample PNVP-co-PSMA 40-60.

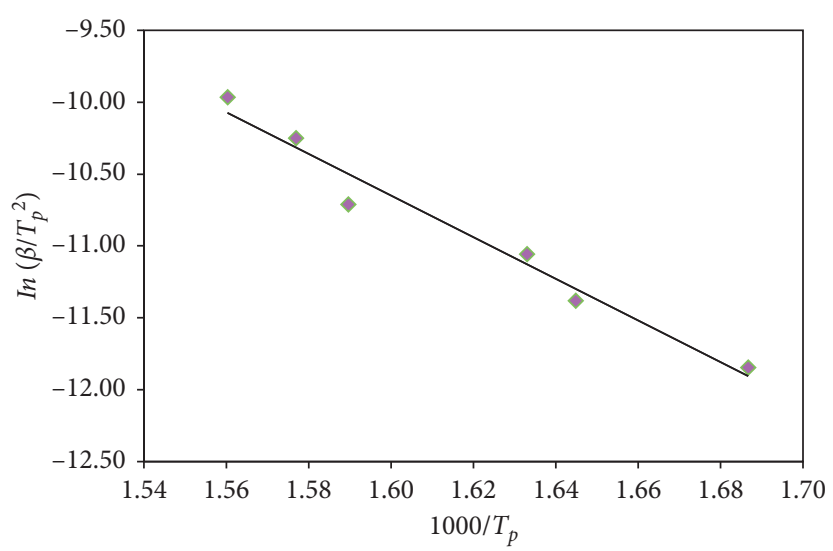

FIgUre 4: Kissinger plot $\ln \left(\beta / T_{p}^{2}\right)$ versus $1000 / T_{\mathrm{p}}$ for sample PNVP-co-PHMA 60-40.

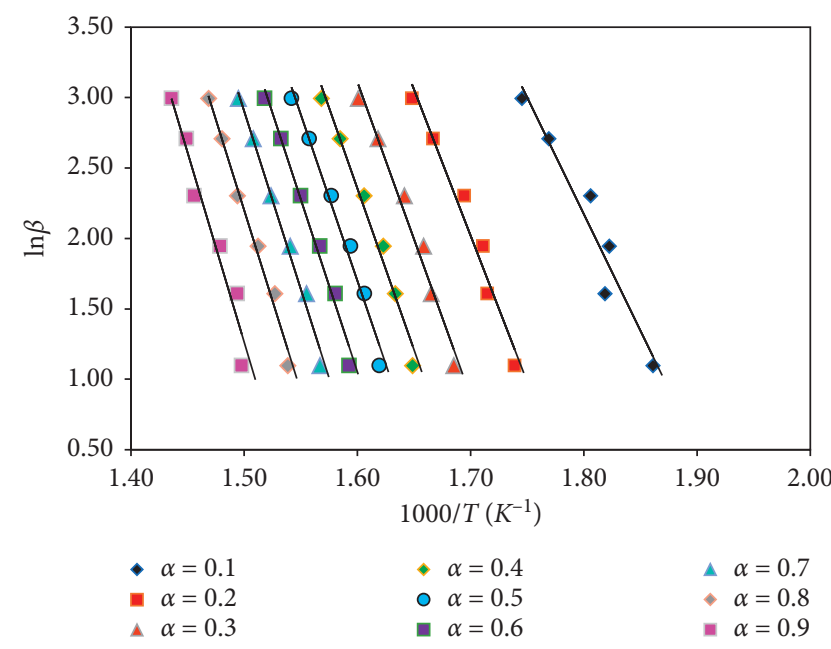

Figure 5: OFW plots $\ln \beta$ versus $1000 / \mathrm{T}$ for sample PNVP-coPSMA 50-50.

The fact that the Kissinger approach only provides the average activation energy of the total procedure of the thermal 


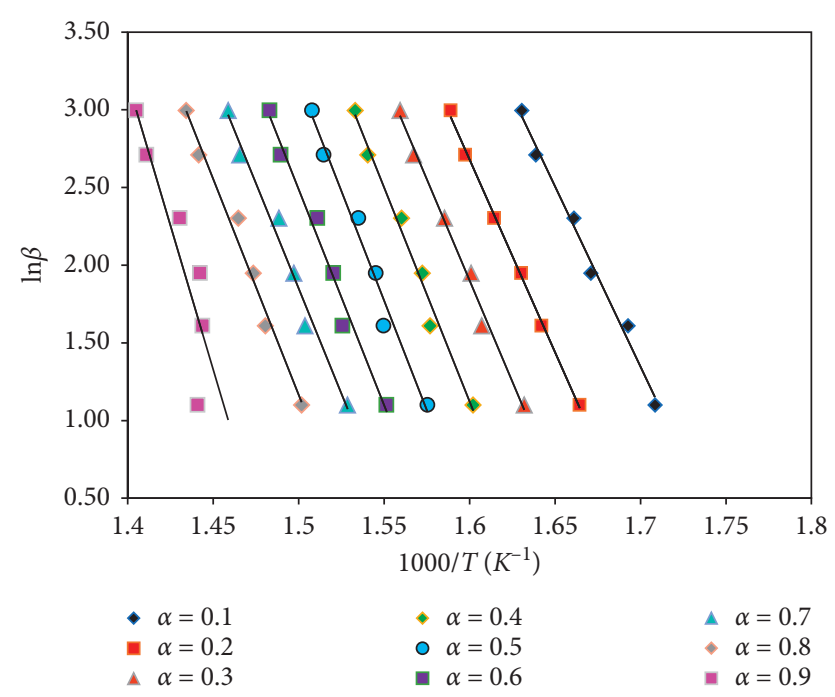

Figure 6: OFW plots $\ln \beta$ versus 1000/T for sample PNVP-coPHMA 80-20.

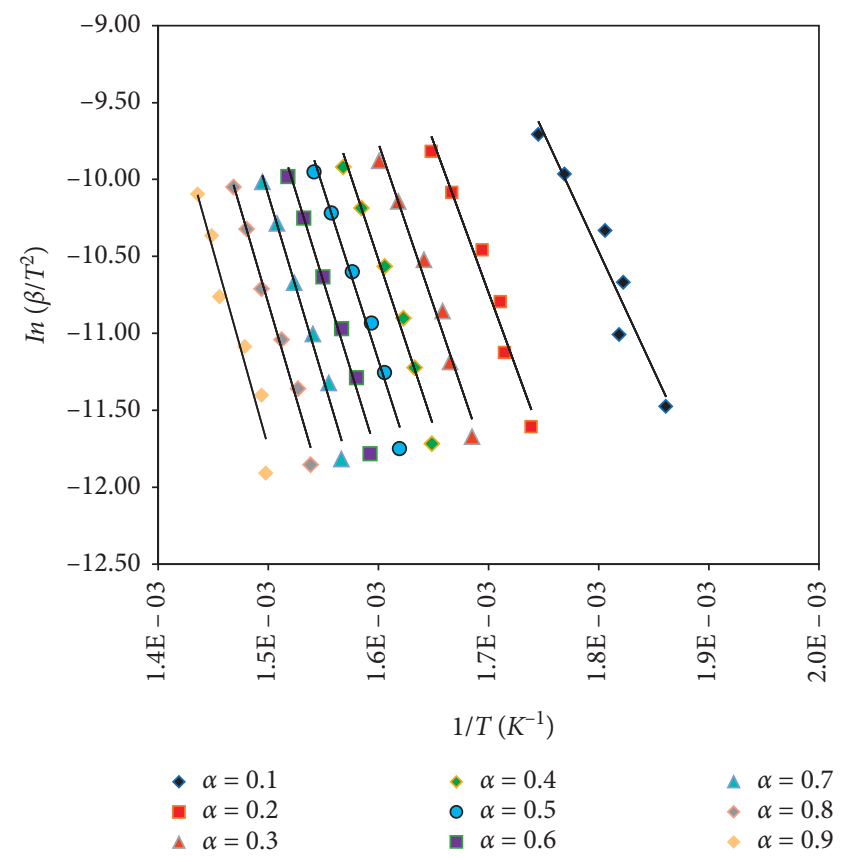

Figure 7: KAS plots $\ln \left(\beta / T^{2}\right)$ versus $1 / \mathrm{T}$ for sample PNVP-coPSMA 50-50.

decomposition seems to introduce high levels of uncertainties and errors. In samples with a complex mechanism of thermal decomposition, the Kissinger methodology fails to give the full picture of the thermal decomposition process.

From the discussion above, it is evident that the OFW and the KAS methodologies are more appropriate to provide precise and detailed insight to the decomposition process, since data are available for different steps of the thermal degradation procedure for each copolymer. For all samples, it is obvious that there is a variation of the $E \alpha$ values with conversion, confirming the complex mechanism of the decomposition reaction. These values are generally between

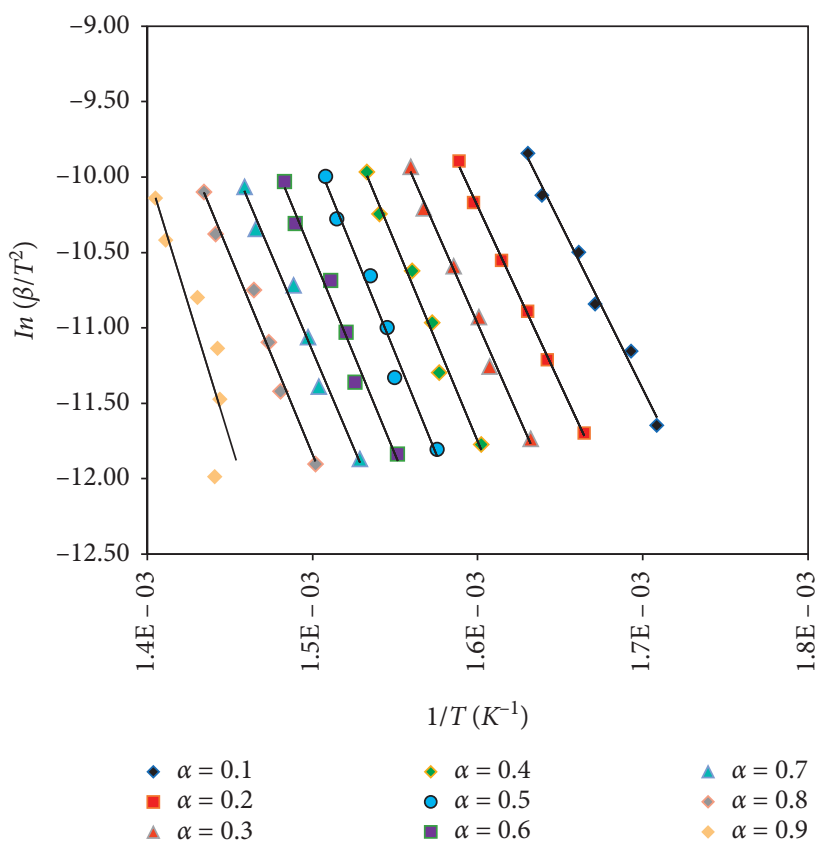

FIgURE 8: KAS plots $\ln \left(\beta / T^{2}\right)$ versus $1 / \mathrm{T}$ for sample PNVP-coPHMA 80-20.

TABle 2: Activation energies by the Kissinger method for the homopolymers and the statistical copolymers.

\begin{tabular}{lc}
\hline Sample & $E \alpha, \mathrm{KJ}$ \\
\hline PSMA & $92.52 \pm 5$ \\
PHMA & $113.11 \pm 6$ \\
PNVP & $198.95 \pm 10$ \\
PBzMA & $185.79 \pm 9 / 203.35 \pm 11$ \\
PDMAEMA & $104.32 \pm 6 / 216.90 \pm 12$ \\
PNVP-co-PSMA 20-80 & $208.80 \pm 11$ \\
PNVP-co-PSMA 40-60 & $255.65 \pm 15$ \\
PNVP-co-PSMA 50-50 & $176.25 \pm 8$ \\
PNVP-co-PSMA 60-40 & $350.66 \pm 19$ \\
PNVP-co-PSMA 80-20 & $214.10 \pm 13$ \\
PNVP-co-PHMA 20-80 & $96.28 \pm 5$ \\
PNVP-co-PHMA 40-60 & $92.23 \pm 5$ \\
PNVP-co-PHMA 50-50 & $156.23 \pm 8$ \\
PNVP-co-PHMA 60-40 & $120.43 \pm 6$ \\
PNVP-co-PHMA 80-20 & $75.47 \pm 4$ \\
\hline
\end{tabular}

those obtained for the respective homopolymers. However, they are closer to those measured for the PNVP homopolymer, despite the fact that the copolymers' composition in PNVP is lower than the polymethacrylates. In other words, this result implies that the incorporation of even a few monomer units of NVP considerably increases the thermal stability of the copolymers. Comparing the data from the KAS and the OFW approaches, it is clear that the results of the activation energies are in close proximity. Nevertheless, the first method provides $E \alpha$ values 5\% to $7 \%$ lower than those of the OFW method. This is reasonable, since these methods are based on relatively different approximations. However, the KAS equation is considered to 
TABLe 3: Activation energies (KJ) by the OWF method for the PNVP-co-PSMA copolymers.

\begin{tabular}{|c|c|c|c|c|c|c|c|}
\hline Conversion $\alpha$ & PSMA & $20-80$ & $40-60$ & $50-50$ & $60-40$ & $80-20$ & NVP \\
\hline 0.1 & $61.88 \pm 3$ & $99.50 \pm 6$ & $151.26 \pm 6$ & $137.63 \pm 5$ & - & - & - \\
\hline 0.2 & $60.57 \pm 3$ & $126.03 \pm 6$ & $176.48 \pm 7$ & $172.61 \pm 7$ & - & $168.32 \pm 7$ & $173.38 \pm 6$ \\
\hline 0.3 & $69.38 \pm 3$ & $133.89 \pm 6$ & $189.37 \pm 8$ & $185.41 \pm 7$ & $161.07 \pm 8$ & $211.46 \pm 9$ & $191.77 \pm 8$ \\
\hline 0.4 & $78.27 \pm 4$ & $144.99 \pm 7$ & $197.89 \pm 9$ & $190.38 \pm 8$ & $188.73 \pm 9$ & $213.74 \pm 9$ & $197.11 \pm 8$ \\
\hline 0.5 & $85.28 \pm 5$ & $156.21 \pm 7$ & $205.68 \pm 9$ & $196.32 \pm 8$ & $207.78 \pm 9$ & $214.91 \pm 9$ & $199.53 \pm 8$ \\
\hline 0.6 & $91.15 \pm 5$ & $165.40 \pm 7$ & $210.18 \pm 9$ & $203.78 \pm 8$ & $219.66 \pm 9$ & $215.27 \pm 9$ & $201.63 \pm 9$ \\
\hline 0.7 & $97.20 \pm 5$ & $171.03 \pm 8$ & $208.86 \pm 9$ & $209.99 \pm 9$ & $224.15 \pm 9$ & $213.15 \pm 9$ & $203.17 \pm 9$ \\
\hline 0.8 & $108.15 \pm 6$ & $169.74 \pm 8$ & $205.86 \pm 9$ & $213.73 \pm 9$ & $219.78 \pm 9$ & $212.87 \pm 9$ & $204.84 \pm 9$ \\
\hline 0.9 & $178.59 \pm 6$ & $164.68 \pm 7$ & $194.31 \pm 8$ & $223.90 \pm 9$ & $209.38 \pm 9$ & $233.11 \pm 10$ & $203.69 \pm 9$ \\
\hline
\end{tabular}

TABle 4: Activation energies (KJ) by the OWF method for the PNVP-co-PHMA copolymers.

\begin{tabular}{|c|c|c|c|c|c|c|c|}
\hline Conversion $\alpha$ & PHMA & $20-80$ & $40-60$ & $50-50$ & $60-40$ & $80-20$ & NVP \\
\hline 0.1 & - & $135.55 \pm 5$ & $150.28 \pm 7$ & $158.16 \pm 7$ & $174.59 \pm 8$ & $193.00 \pm 10$ & - \\
\hline 0.2 & $112.40 \pm 4$ & $134.88 \pm 5$ & $162.36 \pm 7$ & $163.62 \pm 8$ & $174.06 \pm 8$ & $206.30 \pm 12$ & $173.38 \pm 6$ \\
\hline 0.3 & $117.64 \pm 4$ & $131.95 \pm 5$ & $152.58 \pm 7$ & $172.22 \pm 8$ & $178.96 \pm 8$ & $216.56 \pm 12$ & $191.77 \pm 8$ \\
\hline 0.4 & $117.14 \pm 4$ & $130.16 \pm 5$ & $146.93 \pm 7$ & $184.06 \pm 9$ & $193.71 \pm 9$ & $229.11 \pm 12$ & $197.11 \pm 8$ \\
\hline 0.5 & $115.23 \pm 4$ & $157.11 \pm 7$ & $147.55 \pm 7$ & $237.39 \pm 11$ & $221.07 \pm 11$ & $234.57 \pm 12$ & $199.53 \pm 8$ \\
\hline 0.6 & $113.90 \pm 4$ & $136.05 \pm 5$ & $159.63 \pm 7$ & $245.68 \pm 12$ & $252.28 \pm 12$ & $251.12 \pm 12$ & $201.63 \pm 9$ \\
\hline 0.7 & $114.15 \pm 4$ & $148.84 \pm 6$ & $190.26 \pm 8$ & $305.60 \pm 13$ & $268.93 \pm 12$ & $225.13 \pm 11$ & $203.17 \pm 9$ \\
\hline 0.8 & $113.07 \pm 4$ & $184.20 \pm 8$ & $240.14 \pm 11$ & $344.76 \pm 15$ & $256.44 \pm 12$ & $231.00 \pm 12$ & $204.84 \pm 9$ \\
\hline 0.9 & $109.58 \pm 4$ & $243.24 \pm 11$ & $242.29 \pm 11$ & $294.16 \pm 13$ & $251.29 \pm 12$ & $308.23 \pm 13$ & $203.69 \pm 9$ \\
\hline
\end{tabular}

TABle 5: Activation energies (KJ) by the KAS method for the PNVP-co-PSMA copolymers.

\begin{tabular}{|c|c|c|c|c|c|}
\hline Conversion $\alpha$ & $20-80$ & $40-60$ & $50-50$ & $60-40$ & $80-20$ \\
\hline 0.1 & - & $141.97 \pm 7$ & $128.39 \pm 6$ & - & - \\
\hline 0.2 & $116.57 \pm 5$ & $166.74 \pm 8$ & $162.78 \pm 8$ & - & $158.64 \pm 7$ \\
\hline 0.3 & $124.14 \pm 6$ & $179.35 \pm 8$ & $175.28 \pm 8$ & $151.07 \pm 7$ & $201.37 \pm 9$ \\
\hline 0.4 & $135.01 \pm 6$ & $187.66 \pm 9$ & $180.03 \pm 8$ & $178.45 \pm 8$ & $203.38 \pm 9$ \\
\hline 0.5 & $146.04 \pm 7$ & $195.29 \pm 10$ & $185.79 \pm 9$ & $197.30 \pm 9$ & $204.35 \pm 9$ \\
\hline 0.6 & $155.03 \pm 7$ & $199.62 \pm 10$ & $193.11 \pm 9$ & $209.00 \pm 9$ & $204.52 \pm 9$ \\
\hline 0.7 & $160.47 \pm 8$ & $198.13 \pm 10$ & $199.12 \pm 10$ & $213.30 \pm 9$ & $202.24 \pm 9$ \\
\hline 0.8 & $158.96 \pm 8$ & $194.96 \pm 10$ & $202.67 \pm 10$ & $208.74 \pm 9$ & $201.77 \pm 9$ \\
\hline 0.9 & $153.61 \pm 8$ & $183.16 \pm 9$ & $212.57 \pm 11$ & $198.08 \pm 9$ & $221.77 \pm 11$ \\
\hline
\end{tabular}

TABLe 6: Activation energies (KJ) by the KAS method for the PNVP-co-PHMA copolymers.

\begin{tabular}{|c|c|c|c|c|c|}
\hline Conversion $\alpha$ & $20-80$ & $40-60$ & $50-50$ & $60-40$ & $80-20$ \\
\hline 0.1 & $126.19 \pm 6$ & $140.69 \pm 7$ & $148.44 \pm 7$ & $163.29 \pm 7$ & $183.03 \pm 8$ \\
\hline 0.2 & $125.28 \pm 6$ & $152.54 \pm 7$ & $153.61 \pm 7$ & $164.04 \pm 7$ & $196.08 \pm 9$ \\
\hline 0.3 & $122.20 \pm 6$ & $142.62 \pm 7$ & $162.01 \pm 8$ & $168.76 \pm 7$ & $206.14 \pm 9$ \\
\hline 0.4 & $120.30 \pm 6$ & $136.86 \pm 7$ & $173.70 \pm 8$ & $183.36 \pm 8$ & $218.49 \pm 11$ \\
\hline 0.5 & $105.51 \pm 5$ & $137.34 \pm 7$ & $226.86 \pm 11$ & $210.54 \pm 10$ & $223.77 \pm 11$ \\
\hline 0.6 & $125.92 \pm 6$ & $149.27 \pm 8$ & $234.99 \pm 11$ & $241.50 \pm 12$ & $220.15 \pm 11$ \\
\hline 0.7 & $138.56 \pm 6$ & $179.71 \pm 9$ & $294.73 \pm 15$ & $258.79 \pm 14$ & $213.98 \pm 11$ \\
\hline 0.8 & $173.71 \pm 8$ & $229.03 \pm 11$ & $333.68 \pm 17$ & $245.34 \pm 13$ & $219.66 \pm 11$ \\
\hline 0.9 & $232.43 \pm 11$ & $231.19 \pm 11$ & $282.82 \pm 14$ & $239.92 \pm 13$ & $296.56 \pm 15$ \\
\hline
\end{tabular}


provide more reliable and accurate results compared to the OFW equation.

\section{Conclusions}

The thermal stability and the kinetics of the thermal decomposition of the statistical copolymers of $\mathrm{N}$-vinylpyrrolidone (NVP) with the alkyl methacrylates, hexyl methacrylate (HMA) and stearyl methacrylate (SMA), were studied by Thermogravimetric Analysis (TGA) and Differential Thermogravimetry (DTG). Statistical copolymers of different compositions were studied, and their thermal decomposition behavior was compared to that of the corresponding homopolymers. PNVP was found to be the most thermally stable homopolymer compared to the polymethacrylates. The decomposition mechanism of PNVP is rather simple and involves the formation of monomers or oligomers. On the other hand, more complex decomposition mechanisms were involved for the polymethacrylates including the decomposition of the side ester groups followed by the thermal degradation of the main chain. Single decomposition curves were observed for the PNVP-co-PSMA copolymers, whereas, in the case of the PNVP-co-PHMA copolymers, a shoulder or even a second decomposition peak was obtained, especially at the lower rates of heating. The activation energies of the thermal decomposition were calculated using the Ozawa-Flynn-Wall, OFW, the Kissinger-Akahira-Sunose, KAS, and the Kissinger methodologies. The OFW and Kissinger approaches were found to be reliable for the homopolymers. However, in the case of the copolymers, due to the influence of the different sequences of monomer units and the different mechanisms of decomposition of these monomer units, the Kissinger method fails to accurately describe the kinetics of thermal decomposition. On the contrary, the OFW and KAS methods provide a more detailed picture, since they give data for every step of decomposition. It was found that the presence of NVP units considerably increases the $E \alpha$ values, which are relatively close to those obtained for the PNVP homopolymer.

\section{Data Availability}

The data on the thermal stability and the kinetics of thermal decomposition of the homopolymers and the copolymers are included within this article and the Supplementary Materials section.

\section{Conflicts of Interest}

The authors declare that there are no conflicts of interest regarding the publication of this paper.

\section{Acknowledgments}

This research was cofinanced by Greece and the European Union (European Social Fund-ESF) through the Operational Program "Human Resources Development, Education and Lifelong Learning" in the context of the project "Strengthening Human Resources Research Potential via
Doctorate Research" (MIS-5000432), implemented by the State Scholarships Foundation (IKY).

\section{Supplementary Materials}

(a) Tables S1-S12: the data regarding the range of thermal decomposition, that is, the temperatures of initiation and completion of the thermal decomposition, along with the temperature at the highest rate of thermal decomposition, for all homopolymers and copolymers for all heating rates. (b) Figures S1-S11: the TGA and DTG plots for all samples and for the various heating rates. (c) Figures S12-S22: the Kissinger plots for all samples. (d) Figures S23-S33: the OFW plots for the homopolymers and the copolymers. (e) Figures S34-S41: the KAS plots for the copolymers. . (Supplementary Materials)

\section{References}

[1] D. Teegarden, Polymer Chemistry: Introduction to an Indispensable Science, The National Science Teachers Association Press, Arlington, VA, USA, 2004.

[2] Wiley-VCH Verlag GmbH \& Co. KGaA, Macromolecular Engineering. Precise Synthesis, Materials Properties, Applications, K. Matyjaszewski, Y. Gnanou, and L. Leibler, Eds., Wiley-VCH Verlag GmbH \& Co. KGaA, Weinheim, Germany, 2007.

[3] M. Pitsikalis, S. Pispas, J. W. Mays, and N. Hadjichristidis, "Non-linear block copolymer architectures," Advances in Polymer Science, vol. 135, pp. 1-137, 1998.

[4] N. Hadjichristidis, S. Pispas, M. Pitsikalis, H. Iatrou, and C. Vlahos, "Asymmetric star polymers: synthesis and properties," Advances in Polymer Science, vol. 142, pp. 71-127, 1999.

[5] N. Hadjichristidis, M. Pitsikalis, S. Pispas, and H. Iatrou, "Polymers with complex architecture by living anionic polymerization," Chemical Reviews, vol. 101, no. 12, pp. 3747-3792, 2001.

[6] N. Hadjichristidis, S. Pispas, H. Iatrou, and M. Pitsikalis, "Linking Chemistry and anionic polymerization," Current Organic Chemistry, vol. 6, no. 2, pp. 155-176, 2002.

[7] N. Hadjichristidis, M. Pitsikalis, H. Iatrou, and S. Pispas, "The strength of the macromonomer strategy for complex macromolecular architecture: molecular characterization, properties and applications of polymacromonomers," Macromolecular Rapid Communications, vol. 24, no. 17, pp. 979-1013, 2003.

[8] N. Hadjichristidis, H. Iatrou, M. Pitsikalis, S. Pispas, and A. Avgeropoulos, "Linear and non-linear triblock terpolymers. Synthesis, self-assembly in selective solvents and in bulk," Progress in Polymer Science, vol. 30, no. 7, pp. 725-782, 2005.

[9] N. Hadjichristidis, M. Pitsikalis, and H. Iatrou, "Synthesis of block copolymers," Advances in Polymer Science, vol. 189, pp. 1-124, 2005.

[10] N. Hadjichristidis, H. Iatrou, M. Pitsikalis, and J. Mays, "Macromolecular architectures by living and controlled/living polymerizations," Progress in Polymer Science, vol. 31, no. 12, pp. 1068-1132, 2006.

[11] N. Hadjichristidis, M. Pitsikalis, H. Iatrou, and G. Sakellariou, "Macromolecular architectures by living and controlled/living polymerizations," in Controlled and Living Polymerizations. From Mechanisms to Applications, A. H. E. Müller and 
K. Matyjaszewski, Eds., Wiley VCH, Weinheim, Germany, Article ID 34443, 2009.

[12] S.-L. Bitsi, M. Droulia, and M. Pitsikalis, "Supramolecular triblock copolymers through the formation of hydrogen bonds: synthesis, characterization, association effects in solvents of different polarity," Polymers, vol. 12, no. 2, p. 468, 2020.

[13] G. V. Theodosopoulos, S.-L. Bitsi, and M. Pitsikalis, "Complex brush-like macromolecular architectures via anionic and ring opening metathesis polymerization: synthesis, characterization, and thermal properties," Macromolecular Chemistry and Physics, vol. 219, no. 1, Article ID 1700253, 2018.

[14] S.-L. Bitsi, M. Stogiou, S. Costanzo et al., "Synthesis and characterization of low molar mass end-functionalized homoand copolymers with ureidopyrimidone, UPy groups," Colloid and Polymer Science, vol. 298, no. 6, pp. 637-651, 2020.

[15] M. Pitsikalis and A. F. Maroudas, Synthesis of Complex Macromolecular Architectures by Metallocene and Half-Metallocene Complexes, Transworld Research Network, Trivandrum, India, 2013pp. 1-59, ISBN 978-81-7895-597-1.

[16] G. Theodosopoulos and M. Pitsikalis, "Block copolymers: recent synthetic routes and developments," in Anionic Polymerization: Principles, Practice, Strength, Consequences and Applications, N. Hadjichristidis and A. Hirao, Eds., pp. 541623, Springer, Berlin, Germany, 2015.

[17] G. Theodosopoulos and M. Pitsikalis, "Complex branched polymers," in Anionic Polymerization: Principles, Practice, Strength, Consequences and Applications, N. Hadjichristidis and A. Hirao, Eds., pp. 753-803, Springer, Berlin, Germany, 2015.

[18] N. Hadjichristidis, S. Pispas, and G. A. Floudas, Block Copolymers. Synthetic Strategies, Physical Properties and Applications, Wiley-Interscience, Hoboken, NJ, USA, 2003.

[19] Wiley-Interscience, Developments in Block Copolymer Science and Technology, I. W. Hamley, Ed., Wiley-Interscience, West Sussex, UK, 2004.

[20] F. Huma, Z. Akhter, M. Zafar-Uz-Zaman, and T. Yasin, "Release of dexamethasone from poly (N-vinyl pyrrolidoneco-n-hexyl methacrylate) copolymers of controlled hydrophilicity," Journal of Applied Polymer Science, vol. 128, no. 1, pp. 444-450, 2013.

[21] B. V. Nielsen, T. G. Nevell, E. Barbu, J. R. Smith, G. D. Rees, and J. Tsibouklis, "Multifunctional poly (alkyl methacrylate) films for dental care" Biomed," Mater, vol. 6, Article ID 015003, 2011.

[22] M. Huo, Z. Xu, M. Zeng et al., "Controlling vesicular size via topological engineering of amphiphilic polymer in polymerization-induced self-assembly," Macromolecules, vol. 50, no. 24, pp. 9750-9759, 2017.

[23] X. Yuan, W. Li, Z. Zhu, N. Han, and X. Zhang, "Thermoresponsive PVDF/PSMA composite membranes with micro/ nanoscale hierarchical structures for oil/water emulsion separation," Colloids and Surfaces A: Physicochemical and Engineering Aspects, vol. 516, pp. 305-316, 2017.

[24] S. Zouganelis, I. Choinopoulos, I. Goulas, and M. Pitsikalis, "Statistical copolymers of n-butyl vinyl ether and 2-chloroethyl vinyl ether via metallocene-mediated cationic polymerization. A scaffold for the synthesis of graft copolymers," Polymers, vol. 11, no. 9, pp. 1510-1533, 2019.

[25] G. Makrikosta, D. Georgas, E. Siakali-Kioulafa, and M. Pitsikalis, "Statistical copolymers of styrene and 2-vinylpyridine with trimethylsilyl methacrylate and trimethylsilyloxyethyl methacrylate," European Polymer Journal, vol. 41, no. 47-54, 2005.
[26] K. Kostakis, S. Mourmouris, K. Kotakis, N. Nikogeorgos, M. Pitsikalis, and N. Hadjichristidis, "Influence of the cocatalyst structure on the statistical copolymerization of methyl methacrylate with bulky methacrylates using the zirconocene complex Cp2ZrMe2," Journal of Polymer Science Part A: Polymer Chemistry, vol. 43, no. 15, pp. 3305-3314, 2005.

[27] V. Kotzabasakis, N. Petzetakis, M. Pitsikalis, N. Hadjichristidis, and D. J. Lohse, "Copolymerization of tetradecene- 1 and octene- 1 with silyl-protected 10 -undecen1-ol using a Cs -symmetry hafnium metallocene catalyst. A route to functionalized poly ( $\alpha$-olefins)," Journal of Polymer Science Part A: Polymer Chemistry, vol. 47, no. 3, pp. 876-886, 2009.

[28] P. Driva, P. Bexis, and M. Pitsikalis, "Radical copolymerization of 2-vinyl pyridine and oligo (ethylene glycol) methyl ether methacrylates: monomer reactivity ratios and thermal properties," European Polymer Journal, vol. 47, no. 4, pp. 762-771, 2011.

[29] M. Droulia, A. Anastasaki, A. Rokotas, M. Pitsikalis, and P. Paraskevopoulou, "Statistical copolymers of methyl methacrylate and 2-methacryloyloxyethyl ferrocenecarboxylate: monomer reactivity ratios, thermal and electrochemical properties," Journal of Polymer Science Part A: Polymer Chemistry, vol. 49, no. 14, pp. 3080-3089, 2011.

[30] G. Floros, F. Agrafioti, A. Grigoropoulos et al., "Statistical copolymers of norbornene and 5-vinyl-2-norbornene by a ditungsten complex mediated ring-opening metathesis Polymerization: synthesis, thermal properties, and kinetics of thermal decomposition," Journal of Polymer Science Part A: Polymer Chemistry, vol. 51, no. 22, pp. 4835-4844, 2013.

[31] E. Karra, I. Petrakou, P. Driva, and M. Pitsikalis, "Radical copolymerization of 2-vinyl pyridine with functional methacrylates: monomer reactivity ratios and thermal properties," Macromolecules: An Indian Journal, vol. 9, pp. 68-77, 2013.

[32] C. Nikovia, A.-P. Maroudas, P. Goulis, D. Tzimis, P. Paraskevopoulou, and M. Pitsikalis, "Statistical ring opening metathesis copolymerization of norbornene and cyclopentene by grubbs' 1st-generation catalyst," Molecules, vol. 20, no. 9, pp. 15597-15615, 2015.

[33] A. Kanellou, A. Spilioti, G. V. Theodosopoulos, I. Choinopoulos, and M. Pitsikalis, "Statistical copolymers of benzyl methacrylate and diethylaminoethyl methacrylate: monomer reactivity ratios and thermal properties," Organic \& Inorganic Chemistry Journals, vol. 1, pp. 1-11, 2015.

[34] Wiley-Interscience, Handbook of Radical Polymerization, K. Matyjaszewski and T. P. Davis, Eds., Wiley-Interscience, Hoboken, NJ, USA, 2002.

[35] S. Perrier, "50th anniversary perspective: RAFT polymerization-A user guide," Macromolecules, vol. 50, no. 19, pp. 7433-7447, 2017.

[36] L. Martin, G. Gody, and S. Perrier, "Preparation of complex multiblock copolymers via aqueous RAFT polymerization at room temperature," Polymer Chemistry, vol. 6, no. 27, pp. 4875-4886, 2015.

[37] C. Boyer, V. Bulmus, T. P. Davis, V. Ladmiral, J. Liu, and S. Perrier, "Bioapplications of RAFT polymerization," Chemical Reviews, vol. 109, no. 11, pp. 5402-5436, 2009.

[38] P. J. Roth, C. Boyer, A. B. Lowe, and T. P. Davis, "RAFT polymerization and thiol Chemistry: a complementary pairing for implementing modern macromolecular design," Macromolecular Rapid Communications, vol. 32, no. 15, pp. 1123-1143, 2011.

[39] A. Skandalis and S. Pispas, "PDMAEMA-b-PLMA-bPOEGMA triblock terpolymers via RAFT polymerization and 
their self-assembly in aqueous solutions," Polymer Chemistry, vol. 8, no. 31, pp. 4538-4547, 2017.

[40] E. Mitsoni, N. Roka, and M. Pitsikalis, "Statistical copolymerization of $\mathrm{N}$-vinyl-pyrrolidone and alkyl methacrylates via RAFT: reactivity ratios and thermal properties," Journal of Polymer Research, vol. 26, p. 118, 2019.

[41] R. Awasthi, S. Manchanda, P. Das et al., Engineering of Biomaterials for Drug Delivery Systems Chap. 9 - Poly (vinylpyrrolidone), A. Parambath, Ed., Woodhead Publishing, Sawston, UK, 2018.

[42] B. M. Baraker and B. Lobo, "Dispersion parameters of cadmium chloride doped PVA-PVP blend films," Journal of Polymer Research, vol. 24, p. 84, 2017.

[43] A. Karatzas, P. Bilalis, H. Iatrou, M. Pitsikalis, and N. Hadjichristidis, "Synthesis of well-defined functional macromolecular chimeras based on poly (ethylene oxide) or poly (N-vinyl pyrrolidone)," Reactive and Functional Polymers, vol. 69, no. 7, pp. 435-440, 2009.

[44] P. Bilalis, G. Zorba, M. Pitsikalis, and N. Hadjichristidis, "Synthesis of poly (n-hexyl isocyanate-b-N-vinylpyrrolidone) block copolymers by the combination of anionic and nitroxide-mediated radical polymerizations: micellization properties in aqueous solutions," Journal of Polymer Science Part A: Polymer Chemistry, vol. 44, no. 19, pp. 5719-5728, 2006.

[45] P. Bilalis, M. Pitsikalis, and N. Hadjichristidis, "Controlled nitroxide-mediated and reversible addition-fragmentation chain transfer polymerization ofN-vinylpyrrolidone: synthesis of block copolymers with styrene and 2-vinylpyridine," Journal of Polymer Science Part A: Polymer Chemistry, vol. 44, no. 1, pp. 659-665, 2006.

[46] J. I. Ngadaonye, M. O. Cloonan, L. M. Geever, and C. L. Higginbotham, "Synthesis and characterisation of thermo-sensitive terpolymer hydrogels for drug delivery applications," Journal of Polymer Research, vol. 18, no. 6, pp. 2307-2324, 2011.

[47] H. L. Abd El-Mohdy and S. Ghanem, "Biodegradability, antimicrobial activity and properties of PVA/PVP hydrogels prepared by $\gamma$-irradiation"” Journal of Polymer Research, vol. 16, no. 1-10, 2009.

[48] T.-T. Su, H. Jiang, and H. Gong, "Thermal stabilities and thermal degradation kinetics of a styrene-butadiene-styrene star block copolymer," Polymer-Plastics Technology and Engineering, vol. 48, no. 5, pp. 535-541, 2009.

[49] S. D. Genieva, L. T. Vlaev, and A. N. Atanassov, "Study of the thermooxidative degradation kinetics of poly (tetrafluoroethene) using iso-conversional calculation procedure," Journal of Thermal Analysis and Calorimetry, vol. 99, no. 2, pp. 551-561, 2010.

[50] J. Cai, Y. Chen, and R. Liu, "Isothermal kinetic predictions from nonisothermal data by using the iterative linear integral isoconversional method," Journal of the Energy Institute, vol. 87, no. 3, pp. 183-187, 2014.

[51] A. Singh, G. Kaur, C. Sarkar, and N. Mukherjee, "Investigations on chemical, thermal decomposition behavior, kinetics, reaction mechanism and thermodynamic properties of aged TATB," Central European Journal of Energetic Materials, vol. 15, no. 2, pp. 258-282, 2018.

[52] S. Vyazovkin and N. Sbirrazzuoli, "Isoconversional kinetic analysis of thermally stimulated processes in polymers," Macromolecular Rapid Communications, vol. 27, no. 18, pp. 1515-1532, 2006.

[53] S. Vyazovkin, K. Chrissafis, M. L. Di Lorenzo et al., "ICTAC Kinetics Committee recommendations for collecting experimental thermal analysis data for kinetic computations," Thermochimica Acta, vol. 590, pp. 1-23, 2014.

[54] S. Vyazovkin, A. K. Burnham, J. M. Criado, L. A. PérezMaqueda, C. Popescu, and N. Sbirrazzuoli, "ICTAC Kinetics Committee recommendations for performing kinetic computations on thermal analysis data," Thermochimica Acta, vol. 520, no. 1-2, pp. 1-19, 2011.

[55] D. Trache, "Comments on "thermal degradation behavior of hypochlorite-oxidized starch nanocrystals under different oxidized levels"' Carbohydrate Polymers, vol. 151, pp. 535537, 2016.

[56] G. Moad, E. Rizzardo, and S. H. Thang, "Living radical polymerization by the RAFT process - a third update," Australian Journal of Chemistry, vol. 65, no. 8, pp. 985-1076, 2012.

[57] A. Tripathi and A. K. Srivastava, "Studies on the radical polymerization of $\mathrm{N}$-vinyl 2-pyrrolidone initiated by diphenyl ditelluride," Journal of Polymer Research, vol. 15, no. 3, pp. 187-193, 2008.

[58] M. I. Loría-Bastarrachea, W. Herrera-Kao, J. V. CauichRodríguez, J. M. Cervantes-Uc, H. Vázquez-Torres, and A. Ávila-Ortega, "A TG/FTIR study on the thermal degradation of poly (vinyl pyrrolidone)," Journal of Thermal Analysis and Calorimetry, vol. 104, no. 2, pp. 737-742, 2011.

[59] N. Roka and M. Pitsikalis, "Statistical copolymers of $\mathrm{N}$-vinylpyrrolidone and benzyl methacrylate via RAFT: monomer reactivity ratios, thermal properties and kinetics of thermal decomposition," Journal of Macromolecular Science, Part A, vol. 55, no. 3, pp. 222-230, 2018.

[60] N. Roka, O. Kokkorogianni, and M. Pitsikalis, "Statistical copolymers of $\mathrm{N}$-vinylpyrrolidone and 2-(dimethylamino) ethyl methacrylate via RAFT: monomer reactivity ratios, thermal properties, and kinetics of thermal decomposition," Journal of Polymer Science Part A: Polymer Chemistry, vol. 55, no. 22, pp. 3776-3787, 2017.

[61] A. Galukhin, T. Liavitskaya, and S. Vyazovkin, "Kinetic and mechanistic insights into thermally initiated polymerization of cyanate esters with different bridging groups" Macromol," Chemical Physics, vol. 220, Article ID 1900141, 2019.

[62] M. K. Boulkadid, S. Touidjine, D. Trache, and S. Belkhiri, "Analytical methods for the assessment of curing kinetics of polyurethane binders for high-energy composites," Critical Reviews in Analytical Chemistry, vol. 1-10, p. 1, 2020.

[63] A. F. Tarchoun, D. Trache, T. M. Klapötke et al., "A promising energetic polymer fromPosidonia oceanicaBrown algae: synthesis, characterization, and kinetic modeling," Macromolecular Chemistry and Physics, vol. 220, no. 22, Article ID 1900358, 2019.

[64] L. Liqing and C. Donghua, "Application of iso-temperature method of multiple rate to kinetic analysis," Journal of Thermal Analysis and Calorimetry, vol. 78, no. 1, pp. 283-293, 2004.

[65] A. C. R. Lim, B. L. F. Chin, Z. A. Jawad, and K. L. Hii, "Kinetic analysis of rice husk pyrolysis using kissinger-akahira-sunose (KAS) method," Procedia Engineering, vol. 148, pp. 12471251, 2016.

[66] F. Hayoune, S. Chelouche, D. Trache, S. Zitouni, and Y. Grohens, "Thermal decomposition kinetics and lifetime prediction of a PP/PLA blend supplemented with iron stearate during artificial aging," Thermochimica Acta, vol. 690, Article ID 178700, 2020.

[67] D. Trache, A. Abdelaziz, and B. Siouani, "A simple and linear isoconversional method to determine the pre-exponential factors and the mathematical reaction mechanism functions," 
Journal of Thermal Analysis and Calorimetry, vol. 128, no. 1, pp. 335-348, 2017.

[68] T. Ozawa, "A new method of analyzing thermogravimetric data," Bulletin of the Chemical Society of Japan, vol. 38, no. 11, pp. 1881-1886, 1965.

[69] J. H. Flynn and L. A. Wall, "A quick, direct method for the determination of activation energy from thermogravimetric data," Journal of Polymer Science Part B: Polymer Letters, vol. 4, no. 5, pp. 323-328, 1966.

[70] T. Ozawa, "Kinetic analysis of derivative curves in thermal analysis," Journal of Thermal Analysis, vol. 2, no. 3, pp. 301-324, 1970.

[71] H. E. Kissinger, "Reaction kinetics in differential thermal analysis," Analytical Chemistry, vol. 29, no. 11, pp. 1702-1706, 1957.

[72] C. D. Doyle, "Kinetic analysis of thermogravimetric data," Journal of Applied Polymer Science, vol. 5, no. 15, pp. 285-292, 1961.

[73] A. W. Coates and J. Redfern, "Kinetic parameters from thermogravimetric data," Nature, vol. 201, pp. 68-69, 1964.

[74] H. E. Kissinger, "Variation of peak temperature with heating rate in differential thermal analysis," Journal of Research of the National Bureau of Standards, vol. 57, no. 4, pp. 217-221, 1956. 